УДК 159.98

\title{
СМЫСЛОВЫЕ КОММУНИКАЦИИ КАК ТИП ВЗАИМОДЕЙСТВИЯ УЧИТЕЛЯ И УЧАЩИХСЯ В «НАШЕЙ НОВОЙ ШКОЛЕ»
}

\author{
Кагермазова Лаура Цараевна
}

Статья посвящена смысловым коммуникациям, существенным составляющим педагогической коммуникации, которые должны пониматься как интенция - актуальное намерение педагога вступить в коммуникацию сучеником, как ценностное взаимодействие с иелью рефлексивно-смыслового выхода за пределы имеющегося знания в новый контекст знания. Смысловая коммуникация предполагает активное включение полученной информации, осмысленной, проинтерпретированной в систему жизненного опыта самих учащихся в период модернизации образования.

Ключевые слова: «Новая школа», смыслообразование, трансформачия смысла, педагогические коммуникации, коммуникативные стратегии.

\section{SENSE COMMUNICATIONS AS A TYPE OF THE INTERACTION OF THE TEACHER AND PUPILS IN “OUR NEW SCHOOL”}

\section{Kagermazova Laura Tsaraevna}

The article deals with sense communications, essential components of pedagogical communication which should be understood as an intension - a teacher's actual intention to enter into a communication with a pupil, as a value interaction for reflexive-sense leaving the available knowledge to a new context of knowledge. Sense communication presupposes active inclusion of the obtained, comprehended, interpreted information in the system of pupils' life experience during the modernization of education.

Keywords: "New School", sense-creation, sense transformation, pedagogical communications, communicative strategies.

Модернизация и инновационное развитие - единственный путь, который позволит России стать конкурентным обществом в мире XXI в., обеспечить достойную жизнь всем нашим гражданам. В условиях решения этих стратегических задач важнейшими качествами личности становятся инициативность, 
способность творчески мыслить и находить нестандартные решения, умение выбирать профессиональный путь, готовность обучаться в течение всей жизни. Все эти навыки формируются с детства.

Школа является критически важным элементом в этом процессе. Главные задачи современной школы - раскрытие способностей каждого ученика, воспитание порядочного и патриотичного человека, личности, готовой к жизни в высокотехнологичном, конкурентном мире. Школьное обучение должно быть построено так, чтобы выпускники могли самостоятельно ставить и достигать серьезных целей, умело реагировать на разные жизненные ситуации.

В Послании Федеральному собранию Дмитрия Анатольевича Медведева говорится: «Ключевая роль в школе принадлежит учителю». В проекте национальной образовательной инициативы «Наша новая школа» указаны направления развития учительского потенциала.

«Новая школа - это институт, соответствующий целям опережающего развития. В школе будет обеспечено изучение не только достижений прошлого, но и технологий, которые пригодятся в будущем. Ребята будут вовлечены в исследовательские проекты и творческие занятия, чтобы научиться изобретать, понимать и осваивать новое, выражать собственные мысли, принимать решения и помогать друг другу, формулировать интересы и осознавать возможности. Новая школа - это школа для всех. В любой школе будет обеспечиваться успешная социализация детей с ограниченными возможностями здоровья, детей-инвалидов, детей, оставшихся без попечения родителей, находящихся в трудной жизненной ситуации. Будут учитываться возрастные особенности школьников, по-разному организовано обучение на начальной, основной и старшей ступени. Новая школа - это новые учителя, открытые ко всему новому, понимающие детскую психологию и особенности развития школьников, хорошо знающие свой предмет. Задача учителя помочь ребятам найти себя в будущем, стать самостоятельными, творческими и уверенными в себе людьми. Чуткие, внимательные и восприимчивые к интересам школьников, открытые ко всему новому учителя - ключевая особенность школы будущего. В такой школе изменится роль директора, повысится степень его свободы и уровень ответственности. Новая школа - это центр взаимодействия как с родителями и местным сообществом, так и с учреждениями культуры, здравоохранения, спорта, досуга, другими организациями социальной сферы. Школы как центры досуга будут открыты в будние и воскресные дни, а школьные праздники, концерты, спектакли, спортивные мероприятия будут местом семейного отдыха. Новая школа - это современная инфраструктура. Школы станут современными зданиями - школами нашей мечты, с оригинальными архитектурными и дизайнерскими решениями, с добротной и функциональной школьной архитектурой - столовой с вкусной 
и здоровой едой, медиатекой и библиотекой, высокотехнологичным учебным оборудованием, широкополосным Интернетом, грамотными учебниками и интерактивными учебными пособиями, условиями для занятий спортом и творчеством. Новая школа - это современная система оценки качества образования, которая должна обеспечивать нас достоверной информацией о том, как работают и отдельные образовательные учреждения, и система образования в целом», - Д. А. Медведев [10, с. 3].

Поэтому сегодня разрабатываются новые подходы к анализу, оценке и управлению качеством образования, личностно-ориентированные технологии, позволяющие подготовить компетентного, осознающего и развивающего свои личностные качества и способности специалиста, владеющего своими личностными ресурсами, способного эффективно решать профессиональные задачи в условиях динамично меняющихся требований к педагогической деятельности. В настоящее время обязательным условием эффективной работы учителя являются, наряду со знаниями своего предмета и основ дидактики, развитие коммуникативной культуры педагогов, сформированность коммуникативных умений учителя. Современная наука, знакомая со смыслом благодаря его исследованию в различных научных ракурсах, могла бы определить образование как процесс, способствующий вхождению человека в образ Я. Заметим, не в знания и не в социум, а в Я. Если в центре образовательного процесса - ребенок, как в гуманистической педагогике прошлого, личность растущего человека, а она и есть его Я, то, определяя образование указанным образом, мы вторгаемся в смысловую сферу человека. Я является источником смысловой деятельности сознания, средоточием взаимно диалогизирующих смыслов, их обращением к своему носителю. В образе Я субъект (мотив) и объект (цель) едины в одном лице. Таким образом, образование выступает в качестве процесса, способствующего вхождению человека в образ Я через интеграцию смыслов культуры, идентификацию с ее ценностями других людей, включая, естественно, и социальные ценности.

С другой стороны, учитывая, что смысл выводит человека за пределы собственного Я, то и образование будет являться не только процессом, обеспечивающим вхождение в образ Я, но и процессом, способствующим выходу за пределы собственного Я.

Во всей целостной структуре учебного процесса смыслообразующий контекст обнаруживает себя как инициация смыслообразующей деятельности учащихся через смысловые коммуникации в виде направленной трансляции смысла от учителя к ученику. Знания о внешнем мире и знания о различных феноменах переживания обучаемого приобретают смысл лишь в отношении к некоторому более широкому информационно-познаваемому 
контексту, в котором именно преподаватель определяет вектор целенаправленного познавательного процесса как смысловой коммуникации. Такой подход позволяет по-новому рассматривать целый ряд категорий, связанных с педагогическими коммуникациями. Так, коммуникативный потенциал личности учителя, который традиционно рассматривается как индивидуально-своеобразный комплекс коммуникативных особенностей педагога (внутриличностных и поведенческих), характеризующих его возможности в осуществлении коммуникативной составляющей педагогической деятельности, необходимо дополнить ценностно-смысловым компонентом, инициирующим смыслообразование учащихся.

Педагогические коммуникации в реальной практике подвергнуты значительным изменениям, сопровождающимся в основном трансформацией воздействий, которые необходимо оказывать на обучаемых как целевую аудиторию [2, с. 124].

Коммуникативная стратегия как работа по управлению смыслами (при всей условности управления тем, что порождается интенциальной сущностью психики) понимается в учебном процессе как стратегия, направленная на управление процессами создания картины мира, свойственной данному сегменту мира, объединенному как единой системой ценностей, так и едиными коммуникативными возможностями. «Чем сильнее эти коммуникативные возможности, тем активнее проходят процессы общего смыслообразования. Мы отличаем коммуникативные процессы от чисто информационных в том же отношении, в каком мы отличаем информационные процессы от собственно технических процессов передачи данных. Коммуникативные потоки выступают как смыслообразующие, а информационные выступают как форма, в которую этот смысл облекается» [6, с. 50].

Данная проблема до сих пор оставалась вне поля зрения, поскольку она не являлась одним из основных практических вопросов современных образовательных технологий. Однако существующие изменения можно обозначить как смену коммуникационных образовательных стратегий, и, безусловно, данная проблема становится одной из важнейших в психолого-педагогическом осмыслении. Коммуникационная стратегия это представленное в технологии ценностно-смысловое намерение и его осуществление, т. е. выбор пространства, типа взаимодействия, совокупности транслируемых смыслов, относительно которого строится система передачи знаний.

Данное исследование призвано восполнить дефицит психологических и педагогических исследований в коммуникативистике, предлагает психологу и педагогу теоретическое и практическое обеспечение психологодидактического механизма выведения учебного процесса на смысловой 
уровень как направленную смысловую трансляцию в условиях взаимодействия учителя и ученика.

Переход на личностно-смысловую парадигму образования создает реальные условия для реализации учебного процесса как группового смыслообразующего контекста. Учебный смыслообразующий контекст понимается как система направленной трансляции смысла, которая инициирует смыслообразование учащихся, т. о. развивает их смысловую сферу (стимулируя личностное развитие в целом) и выводит знание на уровень жизненных и профессиональных ценностей [5, с. 121].

Для реализации этих идей необходимо обратиться к современному психолого-педагогическому направлению «Смысловая дидактика», основанному на интегративном смысловом подходе, который в настоящий период времени является одним из наиболее целостных и перспективных в психологической науке. В рамках этого подхода не только раскрываются основные механизмы, инициирующие познание в учебном процессе, но и дается возможность построения целостной модели, включающей цели, содержание, технологии, влияющие на формирование смысловой сферы обучаемого, на формирование его смысловой самоориентации и смысложизненной концепции через смыслотрансляции, которые становятся обязательным компонентом учебного процесса.

Смысловые коммуникации, существенная составляющая педагогической коммуникации, понимаются как интенция - актуальное намерение педагога вступить в коммуникацию с учеником, как ценностное взаимодействие с целью рефлексивно-смыслового выхода за пределы имеющегося знания в новый контекст рассмотрения, и предполагают активное включение полученной информации, осмысленной и проинтерпретированной, в систему жизненного опыта учащегося.

Психологическим основанием для разработки смысловых коммуникаций как выбора пространства, типа взаимодействия, совокупности транслируемых смыслов, относительно которых строится система передачи знаний, явились идеи организации смыслопоисковой активности человека как условия осмысления жизненного опыта (Р. Р. Каракозов), положения психотехники выбора (Ф. Е. Василюк) и смыслотехники (Д. А. Леонтьев, И. В. Абакумова) $[4$, с. $112 ; 9$, с. 60].

Эти исследования не просто рассматривают естественную динамику развития смысловой сферы личности в процессе развития, выводящую «за скобки произвольную активность самого субъекта», а, прежде всего, акцентируют внимание на динамике и трансформации смысловых структур, систем и процессов при направленном управлении собственными процессами смысловой регуляции, а также на управлении смысловой динамикой у других людей. 
Термин «смыслотехника» выступает как частный случай психотехники и, по словам Д. А. Леонтьева, «это понятие в свое время предлагалось как обозначение гипотетической системы приемов воспитания и коррекции смысловых образований личности» (А. Г. Асмолов, Б. С. Братусь) [7, с. 56; 8, с. 110].

Смыслотехника рассматривается как система воздействия на личность, обуславливающая изменения смысловой динамики, через которую осуществляются любые изменения смысловой сферы.

Направленная трансляция смыслов в учебном процессе осуществляется с помощью приведенных ниже смыслотехник.

1. Воздействие на ченностную среру личности.

Совокупность ценностей личности - это система отношений субъекта к материальным и духовным результатам человеческой деятельности, сводимая к трем основным видам: созидательным ценностям, ценностям осознания и отношения человека к тому, что для него является важным и обладает для него личностным смыслом, и ченностям переживания, проявляемым в чувствах по отношению к явлениям окружающего мира.

Понятие «ценность» применяется для обозначения предметов, явлений, категорий и идей, служащих эталоном качества и идеалом согласно общественным приоритетам определенного этапа развития культуры.

2. Использование идентичности с челью формирования заданного отношения к конкретному объекту.

Самоидентификация - процесс одновременно формирования самого себя и осознания себя - предполагает новый язык восприятия и экспрессии.

Идентичность включает в себя две подсистемы: личностную идентичность и социальную идентичность. Первая - это самоопределение в терминах физических, интеллектуальных и нравственных черт. Вторая определяется принадлежностью человека к различным социальным категориям: расе, национальности, полу и т. д.

3. Использование стимульной мотивации как факторов формирования определенных смыслов через конвенцию.

При этом важно убедиться в том, что у целевой группы - учащихся или студентов - мотивы, ценности и интересы, на которые направлена коммуникативная деятельность педагога, действительно присутствуют.

В самом общем виде, смыслотехники в учебном процессе сводятся к выбору и актуализации ценностей, потребностей ученика или студента, а также его самокатегоризации и конструированию жизненного мира в соответствии с личностными смыслами, смыслообразующими мотивами, смысловыми установками [1, с. 209].

Для разработки технологической схемы трансляции смысла в обучении как модели целостной технологии процесса актуализации личностных смыслов 
учащихся необходим этап разделения их на отдельные функциональные элементы (или уровни) и обозначение иерархических связей между ними. Логика построения целостной системы технологий, ориентированных на активизацию смыслообразования учащихся или студентов, предполагает интенциальность, т. е. соотношение более общих и более частных способов и приемов смыслообразования обучаемых строится по способу «сверху вниз», когда заложенные в учебный процесс технологии более высокого уровня (иерархия: стратегический уровень - тактический уровень - операциональный уровень) определяют специфику методов, способов и приемов, составляющих «шаги» технологий более низкого порядка. Такой подход дает возможность проследить реальную динамику смысловой активности, позволяющей ученику или студенту произвольно строить свои отношения с окружающим миром, другими людьми и с самим собой. Диалог может быть использован как технология развития мотивационно-смысловой сферы школьников в учебном процессе, поскольку именно диалог в качестве учебной технологии является наиболее перспективным для инициирования смыслообразования учащихся в процессе обучения [3, с. 78]. Такой диалог предполагает обращение учителя непосредственно к ценностно-значимому для учащихся опыту, к жизненному миру ребенка через актуализацию личностного смысла, смысловых установок, мотивов, в результате чего происходит направленная трансформация смыслов партнеров коммуникативного взаимодействия, в качестве которых выступают: учитель и ученик, код коммуникации (устный или письменный диалог), реципиент-ученик (его мотивационно-смысловые особенности), результат (обратная связь, выявляющая особенности смыслообразования в данном диалоге).

Эффективность коммуникативной деятельности как направленной трансляции смысла во многом обеспечивается комплексом индивидуальных коммуникативных особенностей преподавателя и проявляется в возможности понять коммуникативную ситуацию, определить уровень ее смысловой насыщенности, правильно в ней сориентироваться и в соответствии с этим сформировать определенную стратегию смысловой трансляции; а также тактическими способностями преподавателя, обеспечивающими смысловую актуализацию и синхронизацию смыслов субъектов учебного процесса, уровень личностного включения обучающегося в процессы направленного познания.

\section{Литература}

1. Абакумова И. В. Смысл как научная категория и влияние его концептуальных интерпретаций на теорию образования и обучения // Научная мысль Кавказа. - 2006. - № 13 (39). 
2. Абакумова И. В., Ефименко В. Н. Содержание учебного процесса как источник смыслообразования личности. - Ростов н/Д: Изд-во РГУ, 2006.

3. Асмолов А. Г. Личность и общение. - М., 1999. - 344 с.

4. Кагермазова Л. Ц. Коммуникативная компетентность преподавателя. Учебно-методические рекомендации. - Нальчик, 2008. - 236 с.

5. КагермазоваЛ. Ц. Основы профессионально-педагогического общения. Краткий курс: Учебное пособие в помощь студентам / Сост. Л. Ц. Кагермазова. - Нальчик: Издательский отдел КБИГИ, 2010. - 260 с.

6. Кагермазова Л. Ц. Типология коммуникативных стилей у будущих учителей // Казанский педагогический журнал. - 2007. - № 6. - С. 49-55.

7. КагермазоваЛ.Ц. Трансформация личностных особенностей студентов будущих педагогов в период модернизации образования // Российский психологический журнал. - 2007. - Т. 4. - № 4. - С. 55-62.

8. Леонтьев Д. А. Психология смысла. - М.: Смысл, 1999.

9. Леонтьев Д. А., Пилипко Н. В. Выбор как деятельность: личностные детерминанты и возможности формирования // Вопросы психологии. 1995. - № 1. - С. 56-68.

10. Медведев Д. А. Национальная образовательная инициатива «Наша новая школа». - 2010. - Пр-271. - 17 с.

\section{References}

1. Abakumova I.V. Smysl kak nauchnaia kategoriia i vliianie ego kontseptual'nykh interpretatsii na teoriiu obrazovaniia i obucheniia [Sense as a scientific category and the influence of its conceptual interpretations on the theory of education and training]. Nauchnaia mysl' Kavkaza - Scientific Thought of the Caucasus, 2006, no. 13 (39).

2. Abakumova I. V., Efimenko V. N. Soderzhanie uchebnogo protsessa kak istochnik smysloobrazovaniia lichnosti [The content of the educational process as a source of the person's sense-creation]. Rostov-on-Don, Rostov State University Publ., 2006.

3. Asmolov A. G. Lichnost' i obshchenie [Personality and communication]. Moscow, 1999. 344 p.

4. Kagermazova L. Ts. Kommunikativnaia kompetentnost' prepodavatelia. Uchebnometodicheskie rekomendatsii [Communicative competence of the teacher. Educational and methodical recommendations]. Nalchik, 2008. 236 p.

5. Kagermazova L. Ts. Osnovy professional'no-pedagogicheskogo obshcheniia. Kratkii kurs: Uchebnoe posobie v pomoshch'studentam [Bases of professionalpedagogical communication. A short course: the textbook for students]. Nalchik, Kabardino-Balkarian Institute of Humanitarian Researches Publ., 2010. 260 p. 
6. Kagermazova L. Ts. Tipologiia kommunikativnykh stilei u budushchikh uchitelei [The typology of communicative styles among future teachers]. Kazanskii pedagogicheskii zhurnal - Kazan Pedagogical Journal, 2007, no. 6, pp. 49-55.

7. Kagermazova L. Ts. Transformatsiia lichnostnykh osobennostei studentov - budushchikh pedagogov v period modernizatsii obrazovaniia [Transformation of personal features of students - future teachers in the period of modernization of education]. Rossiiskii psikhologicheskii zhurnal Russian Psychological Journal, 2007, V. 4, no. 4, pp. 55-62.

8. Leont'ev D. A. Psikhologiia smysla [The psychology of sense]. Moscow, Smysl Publ., 1999.

9. Leont'ev D. A., Pilipko N.V.Vybor kak deiatel'nost': lichnostnye determinanty i vozmozhnosti formirovaniia [Choosing as activity: personal determinants and possibilities of formation]. Voprosy Psychologii-Approaches to Psychology, 1995 , no. 1, pp. 56-68.

10. Medvedev D. A. Natsional'naia obrazovatel'naia initsiativa "Nasha novaia shkola" [The national educational initiative "Our new school"]. 2010, Pr-271 Publ., 17 p. 